\title{
Effective Ways of Enhancing the Quality of Question Generating and Spontaneous Information Search Outside the Classroom
}

\author{
Keita Shinogaya ${ }^{1}$ \\ ${ }^{1}$ Professor, College of Economics, Nihon University, Japan \\ Correspondence: Keita Shinogaya, College of Economics, Nihon University, Japan.
}

Received: November 4, 2020

Accepted: December 21, 2020

Online Published: December 24, 2020

doi:10.5430/ijhe.v10n3p58

URL: https://doi.org/10.5430/ijhe.v10n3p58

\begin{abstract}
This study examined how to enhance the quality of students' question generating and to encourage their spontaneous information searches after classroom instruction in university. The teacher assigned One Minute Paper as homework, and students answered three questions; “Q1: What was the most important thing that you learned today?”, “Q2: What important question remains unanswered?", and "Q3: What information did you search for after the classroom instruction?". While it was necessary to answer Q1 and Q2 for submission, answering Q3 was not necessary and they could answer it if they wished to do so. The teacher, however, realized that some students were not generating questions actively and the quality of their questions were not adequately improved. After 7 weeks, he changed his intervention and gave feedback on some students' questions to enhance their question quantity and quality. The latent growth curve modelling showed that question quality, spontaneous searching behaviour, and the link between question generation and conducting searches increased after the intervention change. The result also showed that post-intervention change slopes were larger for the feedback group than the class without feedback. The results indicate that besides assigning homework tasks, it is also important to connect learning outside along with inside the classroom to enhance question quality and encourage spontaneous information search.
\end{abstract}

Keywords: Learning outside classroom, higher education, self-regulated learning, homework, spontaneous information search, One Minute Paper

\section{Introduction}

\subsection{Learning outside the Classroom in Higher Education}

In deeper learning, it is necessary to learn not only inside the classroom but also outside the classroom. A self-regulated learner deepens their learning through reflection, question generation, and information searches (Zimmermann \& Schunk, 2001; Zimmerman \& Schunk, 2011).

Learning outside the classroom, however, is not included in most higher education curricula (Alleman et al., 2010). Thus, it is hard to expect college students to study outside the classroom spontaneously. Homework can play an important role in this situation. Homework is said to have positive effects on students' academic outcomes (Cooper \& Valentine, 2001; Epstein \& Van Voorhis, 2001), and it had been found to improve their autonomy with regard to learning and learning skills (Cooper, Steenbergen-Hu, \& Dent, 2012). According to Zimmerman and Schunk (2011), learning outside the classroom is an important part of training students to become self-regulated learners.

However, it is difficult to assign homework to students during lectures in large classes because teachers often cannot monitor each student's learning behaviours outside the classroom. We, therefore, focus on this problem and examine how we can enhance learning quantity and a quality outside the classroom.

\subsection{Interventions for Learning outside the Classroom}

Ryan and Hemmes (2005) pointed out that previous studies mainly used self-reporting as an index for learning outside the classroom (Fleming, 2002; Gurung, 2003) and examined the effects of interventions with concrete learning behaviours outside the classroom. Ryan and Hemmes' study focused on a psychology class at a college, and each student's homework assignment received feedback from the teacher. In addition, they assigned bonus points for students' assignments. Their results showed that the assigning of bonus points to homework increased students' homework assignment quality and achievement levels.

Previous studies have examined the effects of directly teaching learning skills to foster self-regulated learning. In 
many cases, college students were expected to act as mutual learners, and university teachers did not teach learning strategies directly (Zimmerman, Bonner, \& Kovach, 1996). However, it is important to teach each learning skill property in order to enhance students' learning quality if they have insufficient learning behaviours.

Regarding this problem, several research studies on self-regulated learning have conducted interventions to help students meet meta-cognitive aspects such as planning and monitoring because they are necessary for the effective performance of homework. For example, a practical research study in a technical school used a tool that helped students check when, where, and how long they worked on homework. The results showed that this intervention enhanced students' self-efficacy with regard to completion of homework and their course grade (Bembenutty, 2009, 2010; Wong, 2005).

Rosário and his colleagues encouraged students to reflect on their own strategy use and goals with regard to learning; their results showed that this intervention enhanced the use of self-regulated learning strategies such as planning and self-efficacy. In addition, they demonstrated the effect of this intervention in various educational environments and countries (Rosário et al., 2010; Rosário et al., 2015).

\subsection{How Can Teachers Increase Students'Spontaneous Searching Behaviours outside the Classroom?}

Previous studies about homework and self-regulated learning have shown the effects of various interventions on students' learning. These findings, however, are not sufficient for educating more self-regulated learners. For example, Ryan and Hemmes (2005) used bonus points to increase students' learning outside the classroom, and this approach was not desirable based on the self-determination theory (Deci \& Ryan, 2012).

Additionally, almost all previous studies on this subject focused only on homework assigned by teachers and on finding ways to increase homework completion rates (Bembenutty, 2009). Thus, these studies have not examined ways to support students in searching for information spontaneously based on their own questions after classroom instruction. Learning is a cyclical and never-ending process. It is continued through reflections on learned content which generate new and deep questions, and through the search for new information based on such generated questions (Zimmerman \& Schunk, 2011; Zion \& Sadeh, 2007). To educate self-regulated learners, it is necessary to focus not only on improving homework completion but also on enhancing the quality of question generation and ways to increase information searches.

In addition, many previous studies conducted interventions in small-sized classes (e.g., Rosário et al., 2010; Rosário et al., 2015; Ryan \& Hemmes, 2005); therefore, findings related to enhancing the quality of learning behaviours outside the classroom in large classes are not sufficient. Recently, active learning has received attention in higher education academic circles, and many studies have examined its effect (Braxton \& Milem, 2000; Joel, 2006; Prince, 2004). Some classes have more than 100 students, and teachers in such large classes often have to use a lecture-type teaching style. In large classes, however, it is difficult for teachers to monitor each student's learning behaviours outside the classroom; therefore, teachers may not task students with completing homework and other learning activities outside the classroom.

\subsection{Applying One Minute Paper as A Homework Assignment}

To encourage students to generate questions and information searches based on their own questions, this study applied One Minute Paper (OMP) as a homework assignment. OMP is an activity where students reflect on their learning in classroom instruction. The two main questions in OMP are "What was the most important thing that you learned today?" and "What important question remains unanswered?" (Angelo \& Cross, 1993; Holtzman, 2007). Spoken and written reflection is essential in learning (Keeling, 2006); furthermore, previous findings of self-explanation and generating questions have shown that higher-order knowledge construction can be achieved through this activity (Chi, Lewis, Reimann, \& Glaser, 1989; King, 1992; King, 1994; Roscoe \& Chi, 2007). Recent studies have insisted that a diary can be used as a tool for self-regulation of learning (Schmitz \& Willin, 2006; Van Eekelen, Boshuizen, \& Vermunt, 2005). Students, however, take several classes in a week, which makes it difficult for them to write in a diary every day. Moreover, this creates additional responsibilities for teachers, who have to check all students' diaries on a daily basis. On the contrary, OMP includes only a few questions that students have to answer once a week. OMP is easier to conduct both for students and teacher and can be applied to classes in higher education as well.

OMP could lead to spontaneous information searches. Research studies on self-regulated learning have shown that monitoring one's own learning can lead to setting the next goal and learning behaviours (Muis, 2007; Zimmerman \& Schunk, 2011); furthermore, the importance of enhancing self-regulated learning through reflection on each element of learning content has been pointed out previously (Wallin \& Adawi, 2018). Reflecting on learned content after each 
classroom instruction may encourage students to monitor their own content-related understanding and questions, so it is expected to increase learning motivation and enhance the search for information. Regarding the link between generating questions and searching for information, this study added a third question: "What information did you search for after the classroom instruction?" This third question was not assigned as a homework task, and the teacher emphasized that students did not have to answer it if they did not wish to.

\subsection{Learning Management System for Managing Students' Learning}

In this study, the teacher tasked students with submitting an OMP in a learning management system (LMS). In the LMS, teachers can conduct various teaching and evaluating activities such as distributing handouts, conducting quizzes, and distributing questionnaires. Teachers can collect data about each student's homework completion and their responses to the OMP through the questionnaire function in the LMS even in large classes.

Numerous universities have adopted LMSs, and many college students have become accustomed to using their various functions (Parkes, Stein, \& Reading, 2015). Furthermore, some researchers have conducted practical studies that combined classroom instruction and an LMS to examine this system's effect on students' motivation and course grades so far (Bonk \& Graham, 2012; Dias \& Diniz, 2014). Some research studies have used OMP online, and they have shown that this activity is effective for enhancing interactions between students and teachers (Vonderwell, 2004). Furthermore, learners' submissions using OMP online can have a significant positive relationship with their grade in the course (Almer et al., 1998; Chizmar \& Ostrosky, 1998; Erickson \& Erickson, 2014).

LMS records are useful because they measure learners' engagement (O'Flaherty \& Phillips, 2015), and the depth of each student's thinking can be analyzed based on their questions. Onoda and Shinogaya (2014) analyzed the quality of students' questions in OMP and divided them into two types. The first one was the "lower-order question" that confirmed a fact (e.g., Where was Dr. Latane from?); the other one was a "higher-order question," which is designed to foster understanding of the relationship between facts (e.g., "How do the balance theory and cognitive dissonance theory differ from each other?") and encourage the application of learned knowledge to students' experience and daily life (e.g. "How can we use supplication effectively as a self-presentation?"). In an LMS, it is easier to collect and analyze the data from students' OMP questions; therefore, this study focused on the quality of the questions generated using OMP.

\subsection{The Purpose of This Study}

This study aimed not only to encourage students' learning behaviours outside the classroom but also to enhance their question generation quality and information searches based on their own questions through OMP. Visualizing learning and supporting students' planning and monitoring activities can improve their homework completion rates (Bembenutty, 2009, 2010; Wong, 2005). These findings show how LMS is helpful because students can check their homework and other tasks in the class they are taking easily.

This study used a learning record in an LMS as an index for learners' engagement and in order to analyze their questions and spontaneous information searches with latent growth curve modelling. This method estimates the patterns of change as a slope factor in the model and interprets the fitness of the model using the structural equation modelling framework (Preacher, Wichman, MacCallum, \& Briggs, 2008). This method is helpful for investigating interindividual differences in intraindividual change over a given time period (McArdle, 1988; Meredith \& Tisak, 1990).

Previous studies about OMP did not examine OMP question quality and ways to link students' question-based learning to their search for information after OMP implementation. Students' completion of OMP activities can decrease dramatically if teachers continue to task them with the same activity over a long period of time (McElroy \& Coman, 2002; Stead, 2005). Examining an effective way to improve students' task completion rates, increasing question generation quality, and encouraging students to search for information based on their own questions are necessary considerations in education.

\section{Methods}

\subsection{Participants}

The participants were 465 college students (age range: 18-21 years) who were enrolled in a Japanese college psychology class. Two classes were conducted each week, and the students chose one class. A total of 211 students chose a Monday class, and 254 students chose a Wednesday class. Each classroom-based lecture was 90 minutes long, and the sessions were conducted over a period of 15 weeks. The same contents, schedules, and lecture styles were used for the two classes. During the 1st week, the teacher explained topics that would be dealt with, schedules, 
lecture styles, and how students' grades would be rated. From the 2nd to the 12th week, he taught various topics from the fields of social psychology (e.g., social cognition, social influence, helping behaviours, attacking behaviours, and so on) and clinical psychology (e.g., mental disease, psych analysis, behavioural therapy, cognitive therapy, and so on). He explained each psychological term that was described in the textbook and provided concrete examples using PowerPoint slides. During each lecture, the teacher provided some opportunities to prompt the students to think more actively (Prince, 2004). For example, the teacher explained the concept of attribution during the lectures on social cognition (2nd week); after that, the teacher questioned the students as follows: "Why do you think student A got the top score on the achievement test? Discuss this with the other students beside you"; the students then discussed various reasons with regard to the event (e.g., "Because he is talented," "Because he cheated," "Because the test was very easy to solve," and so on) with each other for about 5 minutes.

\subsection{Homework}

For homework each week, the teacher tasked students with submitting an OMP to the LMS. The questionnaire function was used to collect the students' submissions. The questions were as follows: "Q1: What was the most important thing that you learned today?"; "Q2: What important question remains unanswered?"; and "Q3: What information did you search for after the classroom instruction?" Students submitted their answers for these three questions in the LMS within a week. Previous studies suggested that selecting some students' answers and sharing them with the class would encourage students to write One Minute Papers even though all students' answers were not selected (Meehlhause, 2016; Stead, 2005). Onoda and Shinogaya (2014) selected two higher-order questions from students' OMP answers in each class and answered to them, showing some results of previous empirical studies, at the beginning of the next class. The Onoda and Shinogaya (2014) study showed that the quality of students' higher-order questions had increased through this feedback activity. This study selected two higher-order questions from OMP, shared them, and then answered to them, showing some results of previous empirical studies, at the beginning of the next classroom instruction (lasting about 10 minutes).

This study aimed to examine how students' questions can be linked to spontaneous searching behaviour; accordingly, the teacher told the students that, while it would be necessary to answer Q1 and Q2 for submission, answering Q3 would not be necessary and they could answer it if they wished to do so. In each class, OMP activity was conducted until the 12th week because, from the 13th to the 15th week, classroom instruction was used to conduct a review of the course content.

\subsection{Problems and Coping}

\subsubsection{Students' Question Generation}

LMS helps teachers check students' answers because it allows them to see all students' responses with regard to the three questions of OMP in an Excel sheet. The teacher realized that some students were not generating questions actively because there were some responses such as "No questions!" and "I could understand all content in the class" for Q2. In addition, the quality of their questions were not adequately improved, suggesting that selecting two students' questions was not sufficient for improving the quality of students' questions. Higher-order question generation skills are necessary for deepening learning. Previous studies have shown that prompts that helped students create questions starting with "why" or "how" were effective in constructing higher-order knowledge (King, 1992; King, 1994).

Considering these findings, this study emphasized the importance of conducting an intervention from the 8th to the 12th week. During this period, the teacher's instruction included discussion of a model for higher-order questions asking "why" or "how" and example questions from previous classroom instruction contents. For example, questions about the contents of the 7th week class, such as "Why can't we use helping behaviours in some situations?" and "How can we begin to help others?" were presented as good models during the class held in the 8th week.

\subsubsection{Information Search Behaviours}

Q3 was not assigned as a necessary task for the two classes. Only about 10 to $20 \%$ of the students answered Q3, and the percentage tended to decrease as the course progressed. There were two possible approaches for solving this problem. However, it was difficult to present both interventions in the class. Thus, each intervention was added one by one in each class held between the 8th week and the 12th week. Table 1 shows the changes in each class. The next subsection details this intervention. 
Table 1. Design of classroom lectures

\begin{tabular}{|c|c|}
\hline Monday class (Instruction group) & Wednesday class (Feedback group) \\
\hline \multicolumn{2}{|c|}{ Week 1 Guidance } \\
\hline \multicolumn{2}{|c|}{ Week 2 to 7 (First intervention) } \\
\hline \multicolumn{2}{|l|}{ Instruction for learning (5minutes) } \\
\hline \multicolumn{2}{|l|}{ Feedback for students' questions } \\
\hline \multicolumn{2}{|l|}{ Lecture ( 85 minutes) } \\
\hline \multicolumn{2}{|c|}{ Explaining each technical term and theory with concrete real-world examples } \\
\hline \multicolumn{2}{|c|}{ Reflection in LMS } \\
\hline \multicolumn{2}{|c|}{ Q1: What was the most important thing you learned in the lecture? (mandatory) } \\
\hline \multicolumn{2}{|c|}{ Q2: What question is unanswered? (mandatory) } \\
\hline \multicolumn{2}{|l|}{ Q3: What did you research after the class? (optional) } \\
\hline \multicolumn{2}{|c|}{ Week 8 to 12 (changed Intervention) } \\
\hline Instruction for learning (10 minutes) & Instruction for learning (10 minutes) \\
\hline Feedback for students' questions & Feedback for students' questions \\
\hline Instruction for generating higher-order questions & Instruction for generating higher-order questions \\
\hline Instruction for linking three learning phases & Feedback for students' researches \\
\hline Lecture (80 minutes) & Lecture (80 minutes) \\
\hline Reflection in LMS & Reflection in LMS \\
\hline \multicolumn{2}{|c|}{ Week 13 to 15 (Follow-up phases) } \\
\hline Debriefing \& reviewin & ntents of previous lectures \\
\hline
\end{tabular}

\subsubsection{Instruction Regarding the Learning Phases}

Learning is a cyclical process, and question generation leads to new learning (Zimmerman \& Schunk, 2011; Zion \& Sadeh, 2007). Learning becomes deeper through the following sequences of learning phases: preparation, classroom instruction, and review. Many students, however, do not recognize that their learning can be deepened through these three phases (Shinogaya, 2018). Students are not expected to search for new information based on question generation if they do not recognize the sequence of the learning phases. Therefore, instruction regarding the learning phases was added to the classes from the 8th week onward. The teacher presented some PowerPoint slides on the sequence of the three learning phases and informed the students that learning could be deepened through all three of these phases, not just one phase. In addition, he emphasized that generating questions at the end of each phase would lead to learning in the next phase and that this process was important for facilitating deeper learning.

\subsubsection{Feedback for the Answers to Q3}

Feedback for students' OMP answers can influence their motivation to reflect on content learned during the classroom lesson (Meehlhause, 2016; Stead, 2005). According to Onoda and Shinogaya (2014), the quality of the question generation changed after the teacher selected some higher-order questions. It was expected that the frequency of students' searching behaviours would increase if the teacher selected some of the students' answers to Q3. Thus, the teacher started to select two answers provided for Q3 and provided additional explanations at the beginning of the next class.

\subsection{Measurement and Variables}

The students answered the three questions as part of a reflection activity after each classroom lesson. Students' answers to each question were recorded in the LMS. The method used for analyzing the data in the LMS is provided in the next subsection.

\subsection{Ethical Considerations}

In educational practice, it is not desirable to provide inequitable interventions to two different classes. This study conducted different interventions for the two classes from the 8th to the 12th week; therefore, the teacher conducted 
a debriefing and provided opposite interventions for each class during the 13th week so that the application of interventions would be balanced. The instructions regarding the learning phases were provided to the Wednesday class, and the feedback for the answers provided to Q3 during the 12th week were provided to the Monday class. In the 13th-week class, the teacher explained the purpose of this study and informed students that the collected data will be analyzed statistically, and their personal information will not be used in the analyses. The teacher also explained that this study did not use students' course performance data, and that the study findings will be presented at some conferences and be incorporated into a research paper to be published in journals. The students were given a questionnaire that asked them whether they would agree to participate in the study. In the questionnaire, they were informed that they could refuse to answer the questionnaire and that their answers would not be tied to their grades in the class. Only data from the participants who responded "Yes" to this item in the questionnaire were used. Consequently, data from 430 students (196 in the instruction group and 234 in the feedback group) were analyzed.

\section{Results}

\subsection{Coding Learning Behaviours outside the Classroom}

This study aimed to increase students' out-of-classroom learning, enhance the quality of generated questions, and encourage students to search for new information based on their own questions. Given this purpose, we coded the students' answers to the three questions as well as the quality of the questions, along with the linkages between their questions and information searches (as shown below). In this study, two college students who were pursuing majors in educational psychology coded all participants' data, and a kappa coefficient of .90 was obtained. After this, the coders discussed the elements that they had coded differently and came to a consensus on the final coding decision.

\subsubsection{Quality of Questions}

According to King $(1992,1994)$ and Onoda and Shinogaya (2014), questions generated by students can be divided into two types: lower-order questions and higher-order questions. Lower-order questions are those whose purpose of which is to confirm facts. Questions such as "Where was Dr. Latane from?" and "I could not understand what 'space movement' means" were assigned as lower-order questions in this study. Higher-order questions are those that help students examine the relationship between facts and to apply the learned knowledge to their own experiences and daily lives. For example, questions such as "How do the balance theory and the cognitive dissonance theory differ from each other?" and "Can a jinx be considered an overestimation of control?" were coded as higher-order questions. Answers such as "No question!" I could understand all content taught in the class," and "I learned many technical terms today. Therefore, I want to review them in more detail after this" were not counted as submissions for Q2 because these descriptions did not involve generating questions.

\subsubsection{The Linkage between Question Generation and Information Searches}

As mentioned before, self-regulated learners can reflect on their learning, the generation of questions, and the deepening of their own learning. This study focused on this process and coded linkages between the students' questions in Q2 and their conduction of information searches in Q3. If students searched for information related to their questions in Q2, it was coded as 1, and if they did not, it was coded as 0. For example, if students' response to Q2 was "[Positive attitude] seemed to decline in the graph for the experiment on mere exposure effect shown in the lecture, I wonder if it means something related to our nature" and responded to Q3 with "The influence of the time and number of exposures has been examined in various experiments. They have shown that, along with the length of time and number of exposures, quality can also affect participants' evaluation and positive attitude"; this means that he or she searched for new information based on their question in Q2, and this instance was, therefore, coded as "1."

\subsection{Latent Growth Curve Modelling}

\subsubsection{Three Theoretical Models}

This study used latent growth curve modelling to analyze patterns of change in students' learning behaviour throughout the 12 weeks. Students cannot be expected to attend all classes because the teachers often cannot check each student's attendance individually. It appears that the intervention's effect on classroom instruction could be influenced gradually over time. Latent Growth Curve Modelling is useful for estimating the patterns of change in this situation. This study assumed three models and compared the fitness of each model to the data.

The first of these models was the "linear model," which assumed that students' learning behaviours would increase gradually and linearly over a period of 12 weeks. In this model, all intercept factor loadings were set as 1 , and the slope factor loadings were set from 0 to 10 (see Figure1-a). The second model was the "flat and linear model," which assumed that there would be no change in the first 7 weeks and that students' learning would gradually increase after the teacher changed the intervention. All intercept factor loadings were set as 1 . Slope factor loadings were set as 0 
until the 7th week, while loadings were set as 1 to 5 from the 8th week to the 12th week (Figure1-b). Latent growth curve modelling's main strength is its analytic flexibility. In a basic latent growth curve model, one slope is assumed. This study, however, changed the intervention from the 8th week onward; thus, it can also be assumed that two different patterns of change occurred over the two periods (Hardy \& Thiels, 2009). The third model was the "Two slopes model," which assumes two latent slope factors. Slope A factor loadings were set from 0 to 5 in the first 7 weeks and as 5, 5, 5, 5, 5 from the 8 th to the 12 th week, while the slope B factor loadings were set as 0 in the first 7 weeks and as 1 to 5 in the last 5 weeks (Figure 1-c).

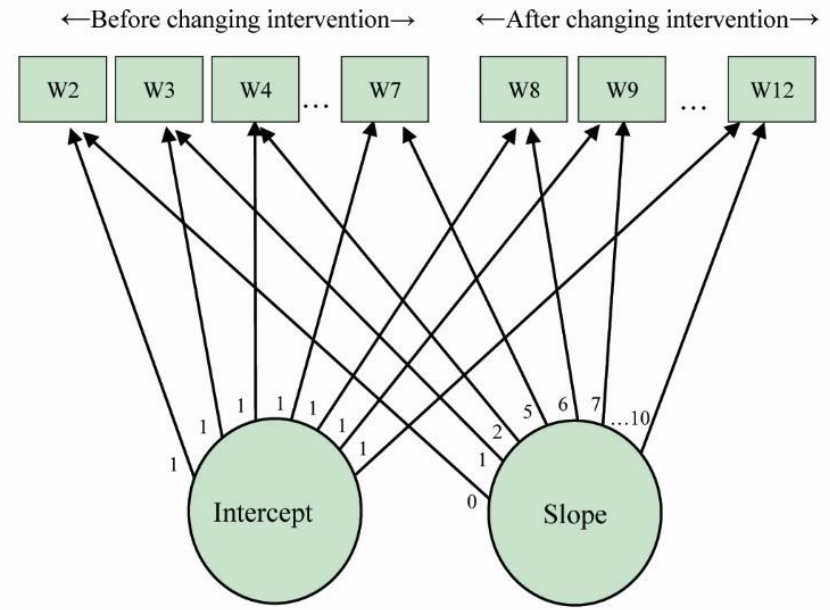

a) Linear Model

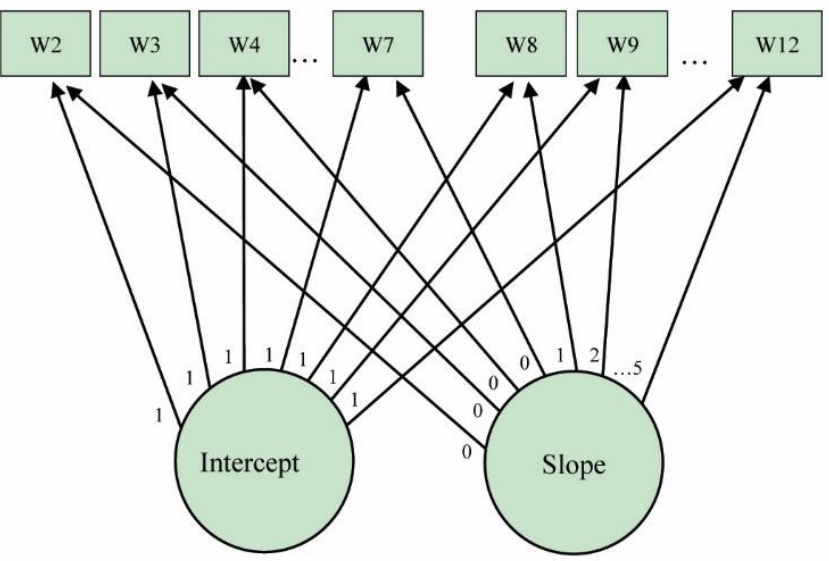

b) Flat \& Linear Model

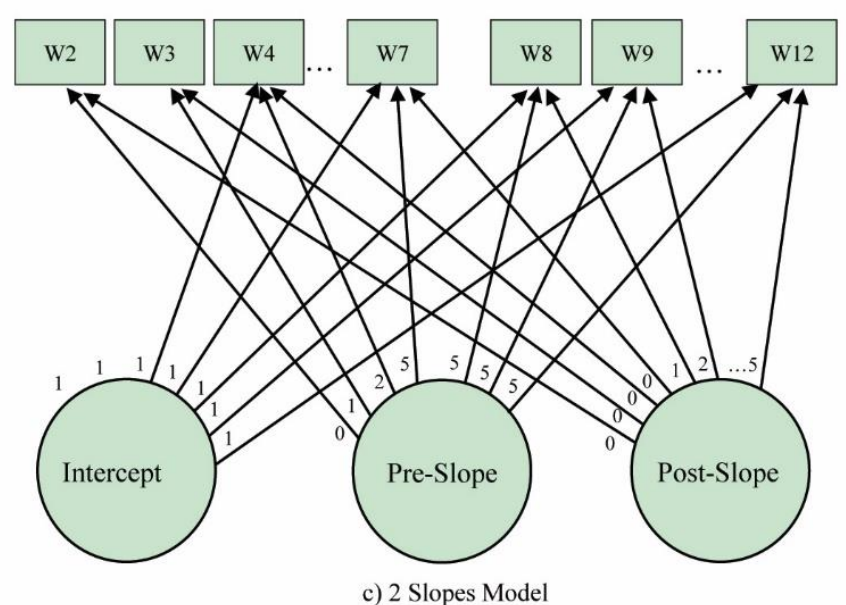

Figure 1. Models compared in this study 
Whenever a best-fitting model was found in each dependent variable, the dummy code showing class difference $(0=$ Monday class, 1 = Wednesday class) was used for assessing the intervention differences in the growth factor variance. Data analysis was conducted with the lavaan package in R (R CORE TEAM, 2019).

Table 2. Number of students in each dependent variables in each week

\begin{tabular}{|c|c|c|c|c|c|c|c|c|c|c|c|}
\hline & \multicolumn{6}{|c|}{ Before changing intervention } & \multicolumn{5}{|c|}{ After changing intervention } \\
\hline & week & week & week & week & week & week & week & week & week & week & week \\
\hline & 2 & 3 & 4 & 5 & 6 & 7 & 8 & 9 & 10 & 11 & 12 \\
\hline \multicolumn{12}{|c|}{ Answering Q1 } \\
\hline IG & 138 & 161 & 163 & 161 & 166 & 164 & 159 & 154 & 167 & 161 & 152 \\
\hline FG & 178 & 201 & 190 & 189 & 199 & 197 & 198 & 195 & 191 & 187 & 178 \\
\hline \multicolumn{12}{|c|}{ Lower-order question } \\
\hline IG & 50 & 50 & 64 & 60 & 58 & 37 & 64 & 55 & 48 & 42 & 44 \\
\hline FG & 79 & 78 & 98 & 71 & 79 & 65 & 94 & 82 & 81 & 57 & 58 \\
\hline \multicolumn{12}{|c|}{ Higher-order question } \\
\hline IG & 34 & 46 & 40 & 42 & 37 & 27 & 32 & 32 & 30 & 51 & 30 \\
\hline FG & 60 & 58 & 60 & 63 & 61 & 55 & 49 & 54 & 66 & 96 & 57 \\
\hline \multicolumn{12}{|c|}{ Information searching } \\
\hline IG & 30 & 28 & 14 & 27 & 22 & 16 & 19 & 20 & 19 & 24 & 22 \\
\hline FG & 50 & 50 & 37 & 37 & 43 & 32 & 43 & 43 & 43 & 61 & 53 \\
\hline \multicolumn{12}{|c|}{ Link between question and searching } \\
\hline IG & 4 & 2 & 2 & 8 & 4 & 3 & 6 & 7 & 8 & 12 & 4 \\
\hline FG & 4 & 4 & 7 & 7 & 15 & 5 & 12 & 18 & 24 & 37 & 19 \\
\hline
\end{tabular}

IG: Instruction group $(n=196)$, FG: Feedback group $(n=234)$

\subsubsection{Responding to the OMP Questions}

The numbers of students in each learning behaviour outside the classroom in all weeks are described in Table 2. The ratio of students who responded to Q1 ("What was the most important thing that you learned today?") was between 70 and $80 \%$ (Figure 2). Table 3 shows that the result of latent growth curve modelling indicated that the linear model had the best fit from the viewpoint of various fitness indexes (CFI $=.993$, RMSEA $=.001$, SRMR $=.089)$. The estimated score was not significant either in the intercept or in the slope. In addition, a follow-up model that assumed class difference as an independent variable was utilized. The results indicated that the dummy code showed no significant relation with the intercepts or slopes (.104 and -.016, respectively). This showed that the ratio of students who responded to Q1 did not change throughout the 12 weeks and that there was no class difference in the means or the slope.

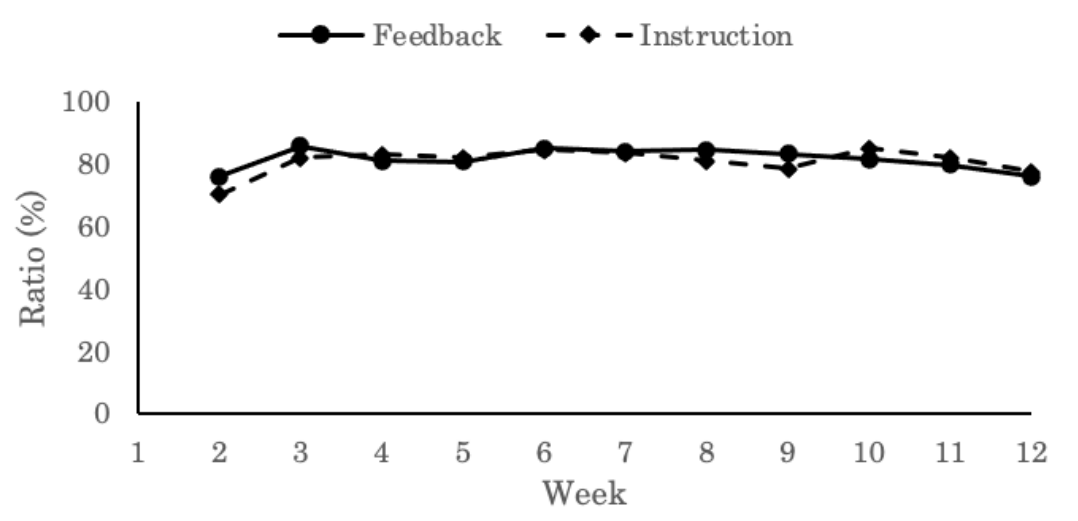

Figure 2 Transition in answering Q1 
Table 3. Result of latent curve model in responding to Q1

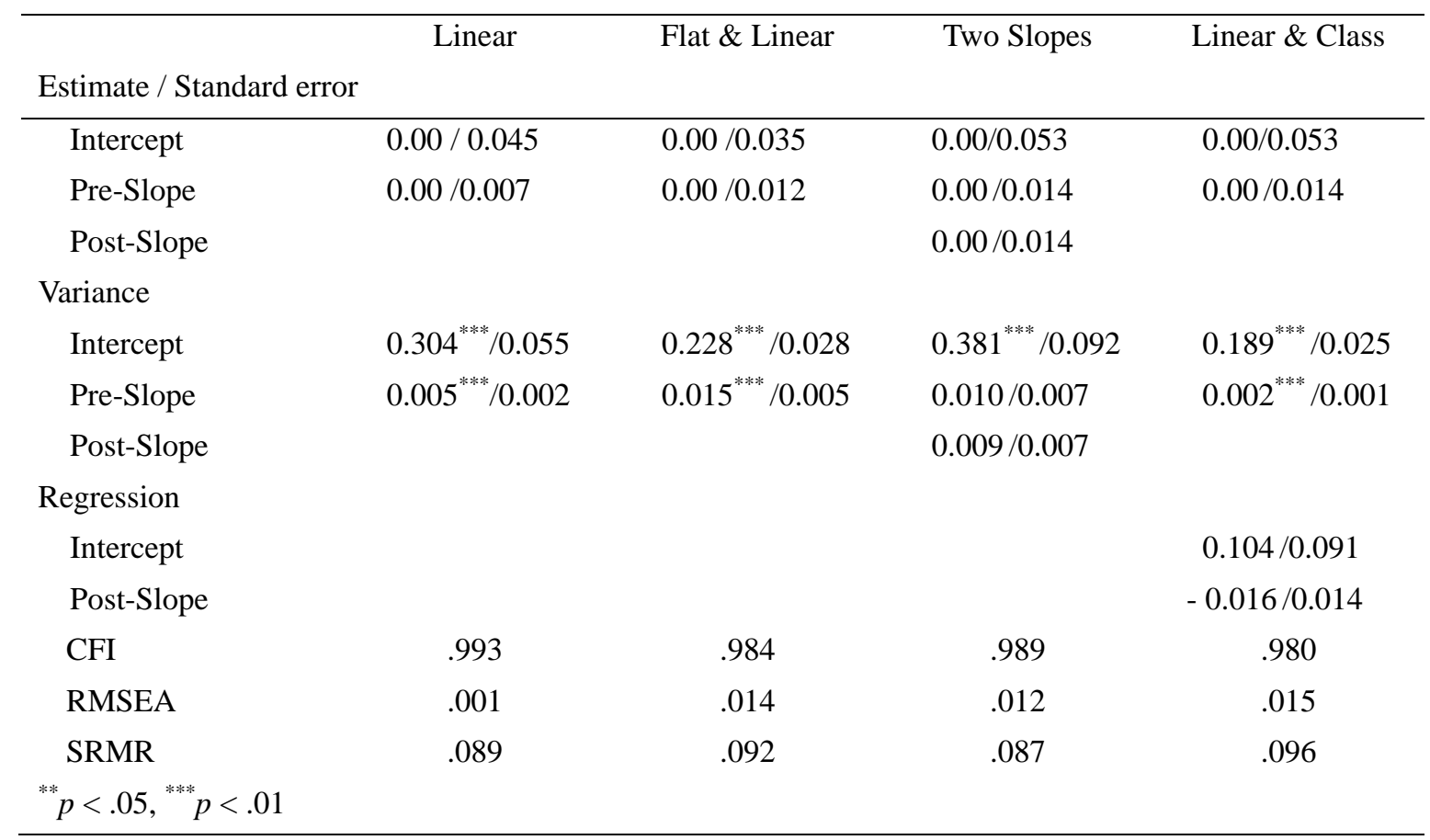

The ratio of students who responded to Q2 ("What important question remains unanswered?") was about $50 \%$. Figure 3 depicts the transition toward generating lower-ordered questions. The result of the latent growth curve modelling showed that the two slopes model had the best fit with the data of lower-order questions $(\mathrm{CFI}=.929$, RMSEA $=.089$, SRMR $=.146$ [see Table 4]). The estimated scores of the intercept and slope, however, were not significant. In the model that assumed class difference as an independent variable, class had a significant influence on intercept $(.196, p<.05)$ and no influence on post-slope $(-.012, n . s$.$) - that is, there was a between-class difference$ in students' tendency to generate lower-order questions originally, although the change pattern was not different between the two classes.

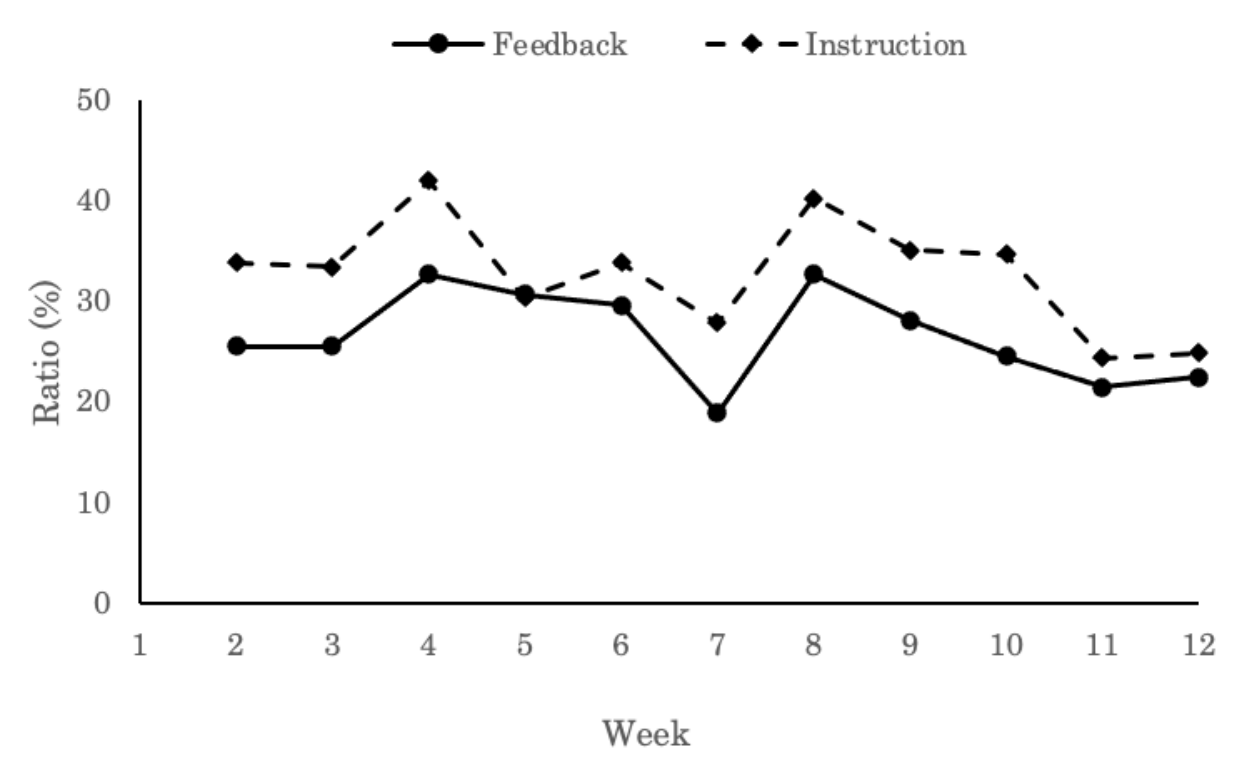

Figure 3. Transition in lower-order question in Q2 
Table 4. Result of latent curve model in lower-order question generating

\begin{tabular}{lcccc}
\hline \multicolumn{1}{c}{ Linear } & Flat \& Linear & Two Slopes & $\begin{array}{l}\text { Two Slopes \& } \\
\text { Class }\end{array}$ \\
\hline \multicolumn{2}{c}{ Estimate / Standard error } & & & \\
Intercept & $0.00 / 0.044$ & $0.00 / 0.038$ & $0.00 / 0.047$ & $0.00 / 0.072$ \\
Pre-Slope & $0.00 / 0.007$ & $0.00 / 0.011$ & $0.00 / 0.012$ & $0.00 / 0.018$ \\
Post-Slope & & & $0.00 / 0.012$ & $0.00 / 0.018$ \\
Variance & & & & \\
Intercept & $0.447^{* * *} / 0.043$ & $0.461^{* * *} / 0.026$ & $0.305^{* * *} / 0.065$ & $0.363^{* * *} / 0.030$ \\
Pre-Slope & $0.003^{* *} / 0.001$ & $0.010^{* *} / 0.003$ & $0.004 / 0.004$ & $0.007^{* * *} / 0.002$ \\
Post-Slope & & & $0.010 / 0.005$ & $0.010 / 0.003$ \\
Regression & & & & $0.196^{* *} / 0.110$ \\
Intercept & & & & $-0.012 / 0.021$ \\
Slope & .919 & .912 & .929 & .923 \\
CFI & .091 & .095 & .089 & .083 \\
RMSEA & .156 & .164 & .146 & .151 \\
SRMR & & & & \\
${ }^{* * *} p<.05,{ }^{* * *} p<.01$ & & & & \\
\hline
\end{tabular}

Figure 4 and Table 5 show that the result indicated that the two slopes model had the best fit with the data of higher-order questions $(\mathrm{CFI}=.997$, RMSEA $=.005$, SRMR $=.129$ ). In addition, the post-slope showed a significant class difference $(0.096, p<.01)$. This suggests that the slope of higher-order questions changed after the intervention was changed; furthermore, the post-slope of the feedback class was significantly higher than that of the instruction class.

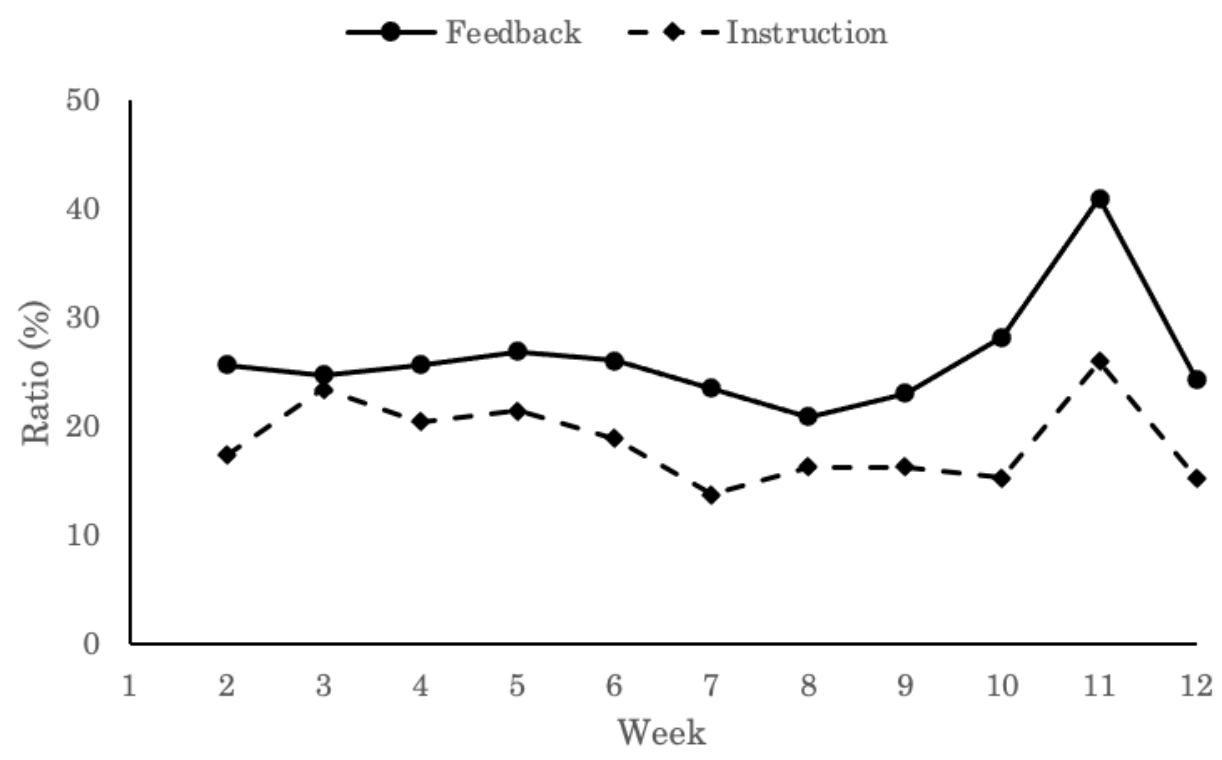

Figure 4. Transition in higher-order question in Q2 
Table 5. Result of latent curve model in higher-order question generating

\begin{tabular}{|c|c|c|c|c|}
\hline & Linear & Flat \& Linear & Two Slopes & $\begin{array}{l}\text { Two slopes \& } \\
\text { Class }\end{array}$ \\
\hline \multicolumn{5}{|c|}{ Estimate / Standard error } \\
\hline Intercept & $0.00 / 0.066$ & $0.00 / 0.051$ & $0.00 / 0.079$ & $0.00 / 0.053$ \\
\hline Pre-Slope & $0.00 / 0.009$ & $0.00 / 0.015$ & $0.00 / 0.023$ & $0.00 / 0.014$ \\
\hline Post-Slope & & & $0.00 / 0.020$ & \\
\hline \multicolumn{5}{|l|}{ Variance } \\
\hline Intercept & $0.481^{* * *} / 0.177$ & $0.332^{* * *} / 0.048$ & $0.606^{* * *} / 0.158$ & $0.288^{* * *} / 0.025$ \\
\hline Pre-Slope & $0.006^{* *} / 0.003$ & $0.014^{* *} / 0.007$ & $0.026 / 0.009$ & $0.003 / 0.004$ \\
\hline Post-Slope & & & $0.016 / 0.009$ & $0.003 / 0.006$ \\
\hline \multicolumn{5}{|l|}{ Regression } \\
\hline Intercept & & & & $0.018 / 0.104$ \\
\hline Post-Slope & & & & $0.096^{* * *} / 0.032$ \\
\hline CFI & .996 & .984 & .997 & .980 \\
\hline RMSEA & .005 & .010 & .005 & .015 \\
\hline SRMR & .139 & .141 & .129 & .096 \\
\hline${ }^{* *} p<.05,{ }^{* * *} p$ & & & & \\
\hline
\end{tabular}

\subsubsection{Changes in Information Search Behaviours}

Figure 5 depicts the transition of students' spontaneous information searches. The ratio of responding to Q3 ("What information did you search for after the classroom instruction?") was about $10 \%$. Table 6 shows the result; the two slopes model was the best-fitting model $(\mathrm{CFI}=1.00, \mathrm{RMSEA}=.000, \mathrm{SRMR}=.034)$. Follow-up analysis indicated that the dummy code of class difference positively affected the intercept $(0.279, p<.05)$ and post-slope $(0.047, p$ $<.05)$. The variance of the post-slope was not significant when class difference was added into the model as an independent variable, but it was significant without class difference as an independent variable. This result suggested that students in the feedback class searched for information more often than those in the instruction class; furthermore, they began to search for information more often after the intervention was changed.

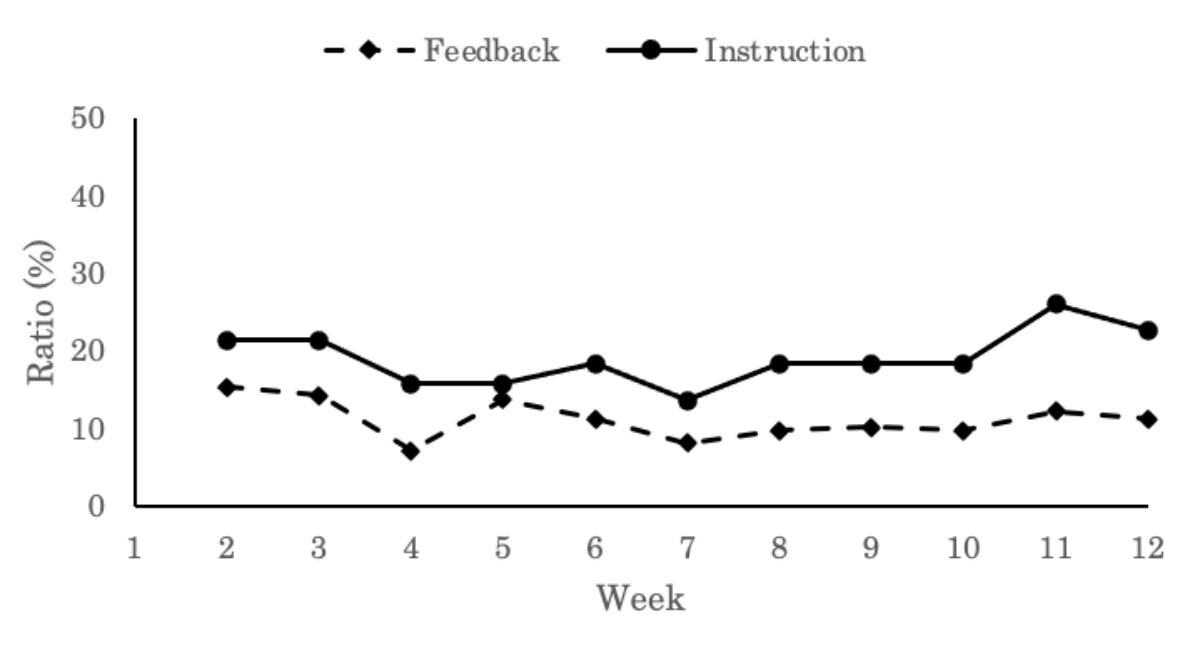

Figure 5. Transition in spontaneous information searches in Q3 
Table 6. Result of latent curve model in searching information

\begin{tabular}{|c|c|c|c|c|}
\hline & Linear & Flat \& Linear & Two Slopes & $\begin{array}{l}\text { Two Slopes \& } \\
\text { Class }\end{array}$ \\
\hline \multicolumn{5}{|c|}{ Estimate / Standard error } \\
\hline Intercept & $0.00 / 0.059$ & $0.00 / 0.057$ & $0.00 / 0.058$ & $0.00 / 0.095$ \\
\hline Pre-Slope & $0.00 / 0.006$ & $0.00 / 0.010$ & $0.00 / 0.012$ & $0.00 / 0.019$ \\
\hline Post-Slope & & & $0.00 / 0.012$ & $0.00 / 0.019$ \\
\hline \multicolumn{5}{|l|}{ Variance } \\
\hline Intercept & $0.792^{* * *} / 0.042$ & $0.817^{* * * *} / 0.025$ & $0.630^{* * *} / 0.056$ & $0.716^{* * *} / 0.032$ \\
\hline Pre-Slope & $0.002^{* *} / 0.001$ & $0.007^{* * * *} / 0.002$ & $0.001 / 0.003$ & $0.006^{* * *} / 0.001$ \\
\hline Post-Slope & & & $0.008^{* *} / 0.003$ & $0.002 / 0.002$ \\
\hline \multicolumn{5}{|l|}{ Regression } \\
\hline Intercept & & & & $0.279^{*} / 0.121$ \\
\hline Slope & & & & $0.047^{*} / 0.025$ \\
\hline CFI & .995 & .993 & 1.00 & .994 \\
\hline RMSEA & .040 & .047 & .000 & .016 \\
\hline SRMR & .056 & .066 & .034 & .079 \\
\hline
\end{tabular}

This study also coded the link between question generation and searching for information and examined how it changed throughout the 12 weeks (Figure 6). The results showed that the two slopes model had the best fit with the data $(\mathrm{CFI}=.988, \mathrm{RMSEA}=.017, \mathrm{SRMR}=.120$, Table 7$)$ and that there were significant individual differences in the intercept and the two slopes. Follow-up analysis indicated that the dummy code of class had significantly affected the post-slope $(0.096, p<.01)$ and that variance in the slope decreased after adding class difference in the model. This result suggests that students in the feedback class began to search for information based on their own questions in Q2 after the teacher changed his intervention.

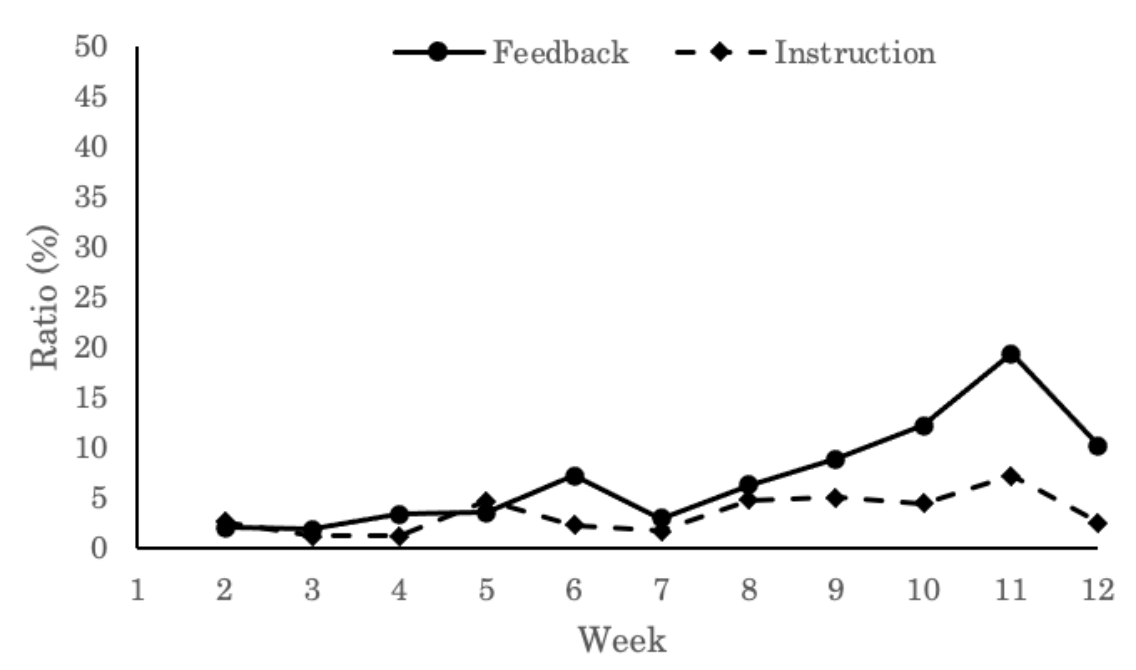

Figure 6. Transition in link between generating question and searching for information 
Table 7. Result of latent curve model in link between question and searching

\begin{tabular}{lcccc}
\hline & Linear & Flat \& Linear & Two Slopes & $\begin{array}{c}\text { Two Slopes \& } \\
\text { Class }\end{array}$ \\
\hline Estimate & & & & \\
Intercept & $0.00 / 0.090$ & $0.00 / 0.070$ & $0.00 / 0.110$ & $0.00 / 0.095$ \\
Pre-Slope & $0.00 / 0.011$ & $0.00 / 0.018$ & $0.00 / 0.029$ & $0.00 / 0.019$ \\
Post-Slope & & & $0.00 / 0.022$ & $0.00 / 0.019$ \\
Variance & & & & \\
Intercept & $0.408^{* * *} / 0.098$ & $0.500^{* * *} / 0.043$ & $0.540^{* * *} / 0.132$ & $0.548^{* * *} / 0.080$ \\
Pre-Slope & $0.003 / 0.003$ & $0.005 / 0.007$ & $0.031^{* *} / 0.013$ & $0.005 / 0.004$ \\
Post-Slope & & & $0.019^{* *} / 0.007$ & $0.002 / 0.005$ \\
Regression & & & & \\
Intercept & & & & $0.168 / 0.143$ \\
Slope & & & & $0.096^{* * *} / 0.037$ \\
CFI & .977 & .963 & .988 & 1.00 \\
RMSEA & .024 & .030 & .017 & 0.00 \\
SRMR & .132 & .147 & & .120 \\
\hline${ }^{* *} p<.05,{ }^{* * *} p<.01$ & & & & \\
\hline
\end{tabular}

\section{Discussion}

\subsection{Students' OMP Submission}

About $70 \%$ of the students answered Q1 and reported what concepts or content they understood in each classroom lesson. The ratio of students who responded to Q1 was lower in this study compared to that found in Ryan and Hemmes (2005), in which students received bonus points, which contributed to their final grade. Considering that the ratio of OMP submissions decreased dramatically when the teachers tasked their students with answering OMP in the same format (McElroy \& Coman, 2002; Stead, 2005), there was a possibility that changing the intervention after 7 weeks would result in maintaining or increasing students' OMP submissions.

Even though the teacher conducted scaffolding in a variety of ways to support the students' question generating, the ratio of submissions for Q2 was a little lower than that for Q1 (about 50\%). It is essential for students to monitor their own understanding and verbalize perceived gaps between new information and prior knowledge, in order to generate questions (Dillon, 2004; van der Meij, 1988). This means that it is necessary to ensure greater support and encouragement for students when teachers task them with generating questions.

\subsection{Changes in Learning Quality outside the Classroom}

According to the latent growth curve modelling, the generation of lower-order questions showed that the two slopes model was the best fit model to the data. This suggests that change pattern can be divided into two parts: before changing the intervention, and after changing the intervention. This did not, however, generate any significant results, which means that the tendency of students generating lower-order questions did not change after the teacher changed his approach to the intervention, and there was no between-class difference. The result of higher-order question generation also showed that the two slopes model was the best fit for the data. This implies that the tendency to generate higher-order questions changed after the intervention was changed. In this study, the teacher added a support procedure taken from King $(1992,1994)$ and incorporated more demonstration of how to generate higher-order questions as well as a model for good questions after the eighth week. Interestingly, follow-up analysis revealed that class difference significantly affected the post-slope (the post-intervention change slope). This finding means that the students' tendency of generating higher-order questions in the feedback group changed more than that in the instruction group after the teacher changed his approach. The teacher selected two answers provided for Q3 and gave additional explanations at the beginning of the next class in the feedback group from the eighth-week onward. Students' information search selected by the teacher was based on higher-order questions. This procedure involved showing the models of higher-order questions more; therefore, it is suggested that students in the feedback group generated higher-order questions after the teacher changed his approach. 
Similar to the result above, the two slopes model presented the best fit for students' information search, and class difference positively affected the post-slope. In addition, this same pattern was observed in the results of the linkage between the generated question and the information search.

Study skills that are taught directly can change students' learning behaviours (Manalo, Uesaka, \& Chinn, 2017; Rosário et al., 2010). In the instruction class, the teacher emphasized the sequence of the learning phases and explained how to deepen learning by generating questions through these phases. This study's results, however, suggested that showing examples of some students' questions and information searches was more important. In the feedback class, the teacher shared some students' information searches and provided additional explanations. Through this procedure, the teacher intended to show the students some good models for generating questions and ways to expand their own learning outside the classroom. Previous studies have suggested that showing concrete examples can enhance students' self-efficacy (Bandura, 1977; Bandura \& Schunk, 1981), and this can improve their quality with regard to question generation and conducting information searches.

\subsection{The Importance of the Study Findings}

This study revealed that directly teaching ways to generate higher-order questions and teachers' feedback to students' spontaneous information searches affected the quality of college students' question generation and encouraged their spontaneous information search activity outside the classroom. Teachers will find this intervention very easy to conduct because it allows them to check their students' answers in an Excel sheet using an LMS. This finding can contribute toward improving educational practices within many universities across the world.

McElroy and Coman (2002) stated that students' OMP submissions decrease when teachers keep tasking them with the same activity. This study's finding suggested that the intervention was effective for maintaining their completion rate for 12 weeks. Furthermore, previous studies on OMP did not examine the OMP question quality. This study divided the students' questions into lower-order questions and higher-order questions and therefore successfully demonstrated how to enhance their question quality.

Furthermore, research studies on self-regulated learning have examined the effects of various interventions on students' learning (Bembenutty, 2009, 2010; Rosário et al., 2010, Rosário et al., 2015; Zimmerman et al., 1996) and how to link students' learning from questions to searching for information after reflection on their learning during the classroom lesson. The learning process occurs in cycles, and a self-regulated learner deepens their learning through reflection, question generating, and more information searches (Zimmerman \& Schunk, 2011; Zimmermann \& Schunk, 2001). This study could thus contribute toward educating students in how to develop learning skills that are valuable even after university graduation.

\subsection{Limitations and Future Perspective}

This study focused on students' spontaneous information searches, but only one information search was conducted during the inquiry cycle. Learning cannot be conducted with information searches alone. In addition, students generated only one question as part of each Q2 after the classroom instruction. Learners generated various questions and information searches, and they searched for new information after obtaining conclusions with regard to the inquiry learning (Zion \& Sadeh, 2007). Rather than focusing on only one searching-related behaviour, future research studies could explore ways to encourage students to maintain their inquiry learning over a long time period.

In addition, many students in this study searched for information only on the internet, and they mostly did not check the reliability of the information they obtained. In modern society, it is important not only to search for information but also to critically assess the reliability of the obtained information. Critical thinking is included among important 21 st century skills and key competencies (see Griffin, McGaw, \& Care, 2012). As mentioned earlier, it is very important to find ways to link learning inside the classroom with learning outside the classroom (Shinogaya, 2018). Previous studies have shown that self-explanation and generating questions enable higher-order knowledge construction (Chi et al., 1989; King, 1992; King, 1994; Roscoe \& Chi, 2007). These findings suggest that students in the feedback group deepen their understanding and constructed higher-order knowledge more than those in the instruction group. According to the procedure of informed consent, however, this study could not use the students' course performance in the analysis. Further studies should expand on this study's findings and examine not just ways to encourage students' spontaneous learning behaviours outside the classroom but also ways to enhance their learning quality and academic performance.

Learning and teaching activities should not be confined only to the classroom. The learning that occurs outside the classroom and the teaching that occurs inside the classroom are not independent from each other. This study thus revealed how teachers monitored students' learning outside the classroom and connected it to their teaching in the 
classroom; it also examined how this practice affected students' spontaneous learning behaviours after 12 weeks of practice. Further research studies should examine more effective ways to establish linkages between learning inside and learning outside the classroom; this will help to educate self-regulated learners.

\section{Conclusion}

This study's findings revealed the effectiveness of giving feedback on some students' learning behaviours in order to encourage students to conduct spontaneous information searches after class. OMP is a helpful homework activity for increasing students' learning outside the classroom, and it allows teachers to check each student's answer easily with an LMS. This study suggested that designing homework tasks and using technologies such as LMS form an important part of education; however, the study findings also indicated that it is important to assess how teachers connect learning inside and outside the classroom.

\section{Acknowledgments}

This work was supported by JSPS KAKENHI under Grant [number 15H01976]. The funding agency had no role in study design; in the collection, analysis and interpretation of data; in the writing of the report; and in the decision to submit the article for publication. I would like to thank Editage, a division of Cactus Communications, for providing proofreading assistance on this document.

\section{References}

Alleman, J., Brophy, J., Knighton, B., Ley, R., Botwinski, B., \& Middlestead, S. (2010). Homework done right: Powerful learning in real-life situations. Thousand Oaks, CA: Corwin Press.

Almer, E. D., Jones, K., \& Moeckel, C. L. (1998). The impact of one-minute papers on learning in an introductory accounting course. Issues in Accounting Education, 13(3), 485-497.

Angelo, T. A., \& Cross, K. P. (1993). Classroom assessment techniques: A handbook for college teachers Hoboken, NJ: Jossey-Bass.

Bandura, A. (1977). Self-efficacy: Toward a unifying theory of behavioral change. Psychological Review, 84(2), 191-215. https://doi.org/10.1037/0033-295X.84.2.191

Bandura, A., \& Schunk, D. H. (1981). Cultivating competence, self-efficacy, and intrinsic interest through proximal self-motivation. Journal of Personality and Social Psychology, 41(3), 586-593. https://doi.org/10.1037/0022-3514.41.3.586

Bembenutty, H. (2009). Self-regulation of homework completion. Psychology Journal, 6(4), 138-153.

Bembenutty, H. (2010). Homework completion: The role of self-efficacy, delay of gratification, and self-regulatory processes. The International Journal of Educational and Psychological Assessment, 6(1), 1-20.

Bonk, C. J., \& Graham, C. R. (2012). The handbook of blended learning: Global perspectives, local designs. Hoboken, NJ: John Wiley \& Sons.

Braxton, J. M., Milem, J. F., \& Sullivan, A. S. (2000). The influence of active learning on the college student departure process: Toward a revision of Tinto's theory. The Journal of Higher Education, 71(5), 569-590. https://doi.org/10.2307/2649260

Chi, M. T. H., Lewis, M. W., Reimann, P., \& Glaser, R. (1989). Self-explanations: How students study and use examples in learning to solve problems. Cognitive Science, 13, 145-182. https://doi.org/10.1016/0364-0213(89)90002-5

Chizmar, J. F., \& Ostrosky, A. L. (1998). The one-minute paper: Some empirical findings. The Journal of Economic Education, 29(1), 3-10. https://doi.org/10.2307/1182961

Cooper, H., Steenbergen-Hu, S., \& Dent, A. L. (2012). Homework. In K. R. Harris, S. Graham, T. Urdan, A. G. Bus, S. Major, \& H. L. Swanson (Eds.), APA handbooks in psychology®. APA educational psychology handbook, Vol. 3. Application to learning and teaching (pp. 475-495). American Psychological Association. https://doi.org/10.1037/13275-019

Cooper, H., \& Valentine, J. C. (2001). Using research to answer practical questions about homework. Educational Psychologist, 36(3), 143-153. https://doi.org/10.1207/S15326985EP3603_1

Deci, E. L., \& Ryan, R. M. (2012). Self-determination theory. In P. A. M. Van Lange, A. W. Kruglanski, \& E. T. Higgins (Eds.), Handbook of theories of social psychology (pp. 416-436). Sage. https://doi.org/10.4135/9781446249215.n21 
Dias, S. B., \& Diniz, J. A. (2014). Towards an enhanced learning management system for blended learning in higher education incorporating distinct learners' profiles. Journal of Educational Technology \& Society, 17(1), 307-319. https://www.jstor.org/stable/jeductechsoci.17.1.307

Dillon, J. T. (2004). Questioning and teaching: A manual of practice. Searcy, AR: Resource Publications.

Epstein, J. L., \& Van Voorhis, F. L. (2001). More than minutes: Teachers' roles in designing homework. Educational Psychologist, 36(3), 181-193. https://doi.org/10.1207/S15326985EP3603_4

Erickson, L. E., \& Erickson, P. A. (2013). Predicting student performance using online one-minute papers. Journal for Economic Educators, 13(1), 6-13.

Fleming, V. M. (2002). Improving students' exam performance by introducing study strategies and goal setting. Teaching of Psychology, 29(2), 115-119. https://doi.org/10.1207/S15328023TOP2902_07

Griffin, P., McGaw, B., \& Care, E. (2012). Assessment and teaching of twenty-first century skills. New York, NY: Springer. https://doi.org/10.1007/978-94-007-2324-5

Gurung, R. A. (2003). Pedagogical aids and student performance. Teaching of Psychology, 30(2), 92-95. https://doi.org/10.1207/S15328023TOP3002_01

Hardy, S. A., \& Thiels, C. (2009). Using latent growth curve modeling in clinical treatment research: An example comparing guided self-change and cognitive behavioural therapy treatments for bulimia nervosa. International Journal of Clinical and Health Psychology, 9(1), 51-71. https://www.redalyc.org/articulo.oa?id=33712020004

Holtzman, R. (2007). Adapting the one-minute paper for active learning. Academic Exhange Quarterly, 11(2), $97-101$.

Joel, M. (2006) Where's the evidence that active learning works? Advances in Physiology Education, 30(4), 159-167. https://doi.org/10.1152/advan.00053.2006

Keeling, R. (2006). The Bologna Process and the Lisbon Research Agenda: the European Commission's expanding role in higher education discourse. European Journal of Education, 41(2), 203-223. https://doi.org/10.1111/j.1465-3435.2006.00256.x

King, A. (1992). Facilitating elaborative learning through guided student-generated questioning. Educational Psychologist, 27(1), 111-126. https://doi.org/10.1207/s15326985ep2701_8

King, A. (1994). Guided knowledge construction in the classroom: Effects of teaching children how to question and how to explain. American Educational Research Journal, 31(2), 338-368. https://doi.org/10.3102/00028312031002338

Manalo, E., Uesaka, Y., \& Chinn, C. A. (2017). Promoting spontaneous use of learning and reasoning strategies: Theory, research, and practice for effective transfer. London: Routledge. https://doi.org/10.4324/9781315564029

McArdle, J. J. (1988). Dynamic but structural equation modeling of repeated measures data. In J. R. Nesselroade \& R. B. Cattell (Eds.), Handbook of multivariate experimental psychology (pp. 561-614). New York, NY: Springer. https://doi.org/10.1007/978-1-4613-0893-5_17

McElroy, B., \& Coman, C. (2002). Writing to learn in managerial accounting classrooms: Further evidence about student performance and perception. Business Quest. https://www.westga.edu/ bquest/2002/writing.htm

Meehlhause, K. (2016). Two parts reflection, one part selfie: A visual alternative to the minute paper. Communications in Information Literacy, 10(1), 14-22. https://doi.org/10.15760/comminfolit.2016.10.1.19

Meredith, W., \& Tisak, J. (1990). Latent curve analysis. Psychometrika, 55(1), 107-122. https://doi.org/10.1007/BF02294746

Muis, K. R. (2007). The role of epistemic beliefs in self-regulated learning. Educational Psychologist, 42(3), 173-190. https://doi.org/10.1080/00461520701416306

O'Flaherty, J., \& Phillips, C. (2015). The use of flipped classrooms in higher education: A scoping review. The Internet and Higher Education, 25, 85-95. https://doi.org/10.1016/j.iheduc.2015.02.002

Onoda, R., \& Shinogaya, K. (2014). Enhancing the quality of learners' reflection: Effects of the teacher's response and interaction with beliefs about reflection. Japanese Journal of Educational Psychology, 62(2), 115-128. https://doi.org/10.5926/jjep.62.115

Parkes, M., Stein, S., \& Reading, C. (2015). Student preparedness for university e-learning environments. The Internet and Higher Education, 25, 1-10. https://doi.org/10.1016/j.iheduc.2014.10.002 
Preacher, K. J., Wichman, A. L., MacCallum, R. C., \& Briggs, N. E. (2008). Latent growth curve modeling. Thousand Oaks, CA: Sage. https://doi.org/10.4135/9781412984737

Prince, M. (2004). Does active learning work? A review of the research. Journal of Engineering Education, 93(3), 223-231. https://doi.org/10.1002/j.2168-9830.2004.tb00809.x

R Core Team. (2019). R: A language and environment for statistical computing. R Foundation for Statistical Computing. https://www.R-project.org/.

Rosário, P., Núñez, J. C., González-Pienda, J., Valle, A., Trigo, L., \& Guimarães, C. (2010). Enhancing self-regulation and approaches to learning in first-year college students: A narrative-based programme assessed in the Iberian Peninsula. European Journal of Psychology of Education, 25(4), 411-428. https://doi.org/10.1007/s10212-010-0020-y

Rosário, P., Núñez, J. C., Trigo, L., Guimarães, C., Fernández, E., Cerezo, R., \& Fulano, C. (2015). Transcultural analysis of the effectiveness of a program to promote self-regulated learning in Mozambique, Chile, Portugal, and Spain. Higher Education Research \& Development, 34(1), 173-187. https://doi.org/10.1080/07294360.2014.935932

Roscoe, R. D., \& Chi, M. T. (2007). Understanding tutor learning: Knowledge-building and knowledge-telling in peer tutors' explanations and questions. Review of Educational Research, 77(4), 534-574. https://doi.org/10.3102/0034654307309920

Ryan, C. S., \& Hemmes, N. S. (2005). Effects of the contingency for homework submission on homework submission and quiz performance in a college course. Journal of Applied Behaviour Analysis, 38(1), 79-88. https://doi.org/10.1901/jaba.2005.123-03

Schmitz, B., \& Wiese, B. S. (2006). New perspectives for the evaluation of training sessions in self-regulated learning: Time-series analyses of diary data. Contemporary Educational Psychology, 31(1), 64-96. https://doi.org/10.1016/j.cedpsych.2005.02.002

Shinogaya, K. (2018). Motives, beliefs, and perceptions among learners affect preparatory learning strategies. Journal of Educational Research, 111(5), 612-619. https://doi.org/ 10.1080/00220671.2017.1349074

Stead, D. R. (2005). A review of the one-minute paper. Active Learning in Higher Education, 6(2), $118-131$. https://doi.org/10.1177/1469787405054237

van der Meij, H. The gratween teacher and student questioning. In S. A. Karabenick (Ed.), Strategic help seeking (pp. 195-218). Mahwah, NJ: Lawrence Erlbaum Associates.

Van Eekelen, I. M., Boshuizen, H. P. A., \& Vermunt, J. D. (2005). Self-regulation in higher education teacher learning. Higher Education, 50(3), 447-471. https://doi.org/10.1007/s10734-004-6362-0

Vonderwell, S. (2004). Assessing online learning and teaching: Adapting the minute paper. TechTrends, 48(4), 29-31. https://doi.org/10.1007/bf02763442

Wallin, P., \& Adawi, T. (2018). The reflective diary as a method for the formative assessment of self-regulated learning. European Journal of Engineering Education, 43(4), 507-521. https://doi.org/10.1080/03043797.2017.1290585

Wong, M. S. L. (2005). Language learning strategies and language self-efficacy: Investigating the relationship in Malaysia. RELC Journal, 36(3), 245-269. https://doi.org/10.1177/0033688205060050

Zimmerman, B. J., Bonner, S., \& Kovach, R. (1996). Developing self-regulated learners: Beyond achievement to self-efficacy. American Psychological Association. https://doi.org/10.1037/10213-000

Zimmerman, B. J., \& Schunk, D. H. (Eds.). (2011). Handbook of self-regulation of learning and performance. Taylor \& Francis. https://doi.org/10.4324/9780203839010

Zimmermann, B. J., \& Schunk, D. (2001). Self-regulated learning and academic achievement: Theory, research and practice. Mahwah, NJ: Lawrence Erlbaum Associates.

Zion, M., \& Sadeh, I. (2007). Curiosity and open inquiry learning. Journal of Biological Education, 41(4), 162-169. https://doi.org/10.1080/00219266.2007.9656092

\section{Copyrights}

Copyright for this article is retained by the author(s), with first publication rights granted to the journal.

This is an open-access article distributed under the terms and conditions of the Creative Commons Attribution license (http://creativecommons.org/licenses/by/4.0/). 